\title{
Changes of time mean state and variability of hydrology in response to a doubling and quadrupling of $\mathrm{CO}_{2}$
}

\author{
Richard T. Wetherald
}

Received: 21 November 2008 / Accepted: 27 August 2009 / Published online: 11 November 2009

(C) The Author(s) 2009. This article is published with open access at Springerlink.com

\begin{abstract}
This paper examines the subject of hydrologic variability and its changes in two separate integrations of a coupled ocean-atmosphere general circulation model developed at the Geophysical Fluid Dynamics Laboratory/NOAA assuming a $1 \%$ per year increase to a doubling and quadrupling of $\mathrm{CO}_{2}$, respectively. Changes in time mean state and variability of precipitation, runoff and soil moisture are evaluated using monthly and seasonal mean data derived from these integrations. Various statistical tests are then performed on the resulting time mean and variability changes. The patterns of hydrologic change for these three quantities are similar to those obtained from previous studies. In northern middle to higher latitudes for the time means, the changes include increases in monthly mean precipitation, increases in monthly mean runoff during the fall, winter and spring seasons and decreases of monthly mean soil moisture during summer. Many of these changes are found to be statistically significant at the $5 \%$ significance level for both the time mean and variability especially for the results where $\mathrm{CO}_{2}$ is quadrupled such as monthly mean precipitation. Significant changes also include increases of runoff variability during spring, winter and spring and increases of soil moisture variability during the summer season. These results support statements made in previous IPCC reports that increasing greenhouse gases can lead to more severe and frequent floods and droughts depending upon season and latitude. This study also indicates that the approaches to equilibrium of these two integrations, and the resulting hydrologic changes, take place over time scales of hundreds of years in agreement with several previous investigations.
\end{abstract}

R. T. Wetherald $(\bowtie)$

Geophysical Fluid Dynamics Laboratory (GFDL), NOAA, Princeton, NJ 08542, USA

e-mail: Dick.Wetherald@noaa.gov 


\section{Introduction}

The time mean response of various aspects of the hydrologic cycle to greenhouse warming scenarios has been extensively studied (e.g. Manabe and Stouffer 1980; Manabe et al. 1981; Manabe and Wetherald 1987; Cubasch et al. 2001; Wetherald and Manabe 2002). However, changes in variability are equally as important as changes in the time mean state in understanding the theoretical response of the hydrologic cycle to increases of greenhouse gases. In particular, such an analysis can provide greater insight into the potential trend of both floods and droughts in a warmer atmosphere. In this investigation, the changes of time mean state and variability of a number of hydrologic variables are examined using the results obtained from two separate integrations developed for the latest 2007 IPCC report in which the $\mathrm{CO}_{2}$ concentration was increased by $1 \%$ per year until it was both doubled and quadrupled, respectively and run out for a total time of 600 years each.

It has been noted in other studies that changes in various hydrologic quantities have small signal to noise ratios as compared with those of temperature (e.g. Cubasch et al. 2001) and therefore very long integrations with a relatively large radiative forcing are necessary for statistical significance to be established. Furthermore, it was noted in studies by Raisanen (2002) and Hunt and Elliot (2004) that changes in precipitation variability were, in general, much smaller than the corresponding time mean changes.

In this investigation, a broader view is taken where monthly and seasonal changes are examined globally. Emphasis is placed upon those variance changes which appear to correspond to large scale changes of the mean state with the implication that there are large scale variance changes that can be related to these time mean changes.

As in a previous variability study involving temperature (Stouffer and Wetherald 2007), use is made of the statistical method of Vinnikov and Robock (2002) to compute the variance time series and the detrending of those series. This method separates the changes of mean climate from those of variance without altering the variance time series themselves. The reader is referred to the Appendix for details of this procedure. Implicit in this study is the belief that if a high degree of confidence can be placed upon the time mean changes, then this allows more confidence to be placed upon the variance changes as well.

The uniqueness of this study is threefold. Although there are a multitude of studies documenting the increase of precipitation variance with its mean with regard to observed natural climate variations and comparing these results with model simulations (see the PCMDI web site under "Subproject Publications"), relatively few of these studies investigate this relationship with regard to anthropogenic greenhouse warming. Examples of the latter include Benestad (2006), and Mearns et al. (1990). Secondly, an attempt is made to analyze changes of time mean state and inter-annual (or seasonal) variability of precipitation, runoff and soil moisture and evaluate their trends through the use of appropriate statistical methods, an investigation that has not been carried out to date. Thirdly, this study attempts to further substantiate statements made in previous and the current 4th Assessment Report of the IPCC (2007) that greenhouse warming has the potential of increasing the frequency and intensity of both floods and droughts. 


\section{Model description and integration procedure}

The model used here is latest version of the coupled ocean-atmospheric model called CM2.1 (Delworth et al. 2006). Here, simply a brief description is given. For more details, the reader is referred to Parts I, II, the Delworth et al. paper and the references contained therein.

Since this paper deals mainly with hydrology, it is worthwhile to describe in more detail both the precipitation and land surface schemes used. The CM2.1 land surface component is described by Milly and Shmakin (2002) and is similar to the Manabe "bucket" scheme (Manabe 1969) except that the uniform $15 \mathrm{~cm}$ field capacity is replaced by a global distribution of field capacities derived from vegetation and soil type data sets. In addition, stomatal resistance or delayed evaporation from plants is accounted for by a simple parameterization. Allowance is made for heat storage over the continents. Precipitation is computed according to the Relaxed ArakawaSchubert formulation of Moorthi and Suarez (1992). In general large-scale clouds and cloud microphysics are determined according to Rotstayn (1997), where cloud is forecast based upon the general scheme by Tiedtke (1993).

Three separate integrations are performed with the CM2.1 model; a control run in which the $\mathrm{CO}_{2}$ concentration is held fixed at 1860 levels (286 ppm), a second run where the $\mathrm{CO}_{2}$ concentration is increased by $1 \%$ per year until it is doubled and a third run where the $\mathrm{CO}_{2}$ concentration is increased by $1 \%$ per year until it is quadrupled. Once these concentrations are reached, they are held fixed at those levels thereafter. Both the doubling of $\mathrm{CO}_{2}$ integration (hereafter called $2 \mathrm{X}$ ) and the quadrupling of $\mathrm{CO}_{2}$ integration (hereafter called $4 \mathrm{X}$ ) were run out for a total of 600 model years each. The corresponding control integration was run for a total of 1000 years. The analysis period for both the $2 \mathrm{X}$ and $4 \mathrm{X}$ transient integrations was taken to be the last 160 years of each run whereas the last 900 years of the control integration were used.

This integration procedure is illustrated by Fig. 1 which shows the time evolutions of global mean surface air temperature (Fig. 1a) and those of total precipitation rate (Fig. 1b). The main feature of this figure is that both global surface air temperature and precipitation rate continue to increase significantly after the two concentrations of $\mathrm{CO}_{2}$ are held constant for several hundred years. The continued response of global mean surface air temperature was referred to as "committed warming" in Wetherald et al. (2001). It is clear that time scales on the order of hundreds of years are necessary for the integrations to achieve complete climatological equilibrium even after the greenhouse gas concentrations are stabilized due primarily to the relatively slow response of the world oceans (e.g. Manabe and Stouffer 1994; Stouffer and Manabe 1999; Stouffer 2004; Stouffer et al. 2006; Cubasch et al. 2001; Wetherald et al. 2001). If a mixed-layer version of CM2.1 is used as an estimate for the equilibrium state of the CM2.1 model (e.g. Stouffer et al. 2006), the 2X integration has achieved approximately $80 \%$ of the expected globally averaged equilibrium response of surface air temperature by the 600th year.

With regard to globally averaged total precipitation rate, increases of approximately $70 \%$ of the expected equilibrium response have been obtained for the $2 \mathrm{X}$ run as compared with the mixed-layer version. The same results are obtained for a 


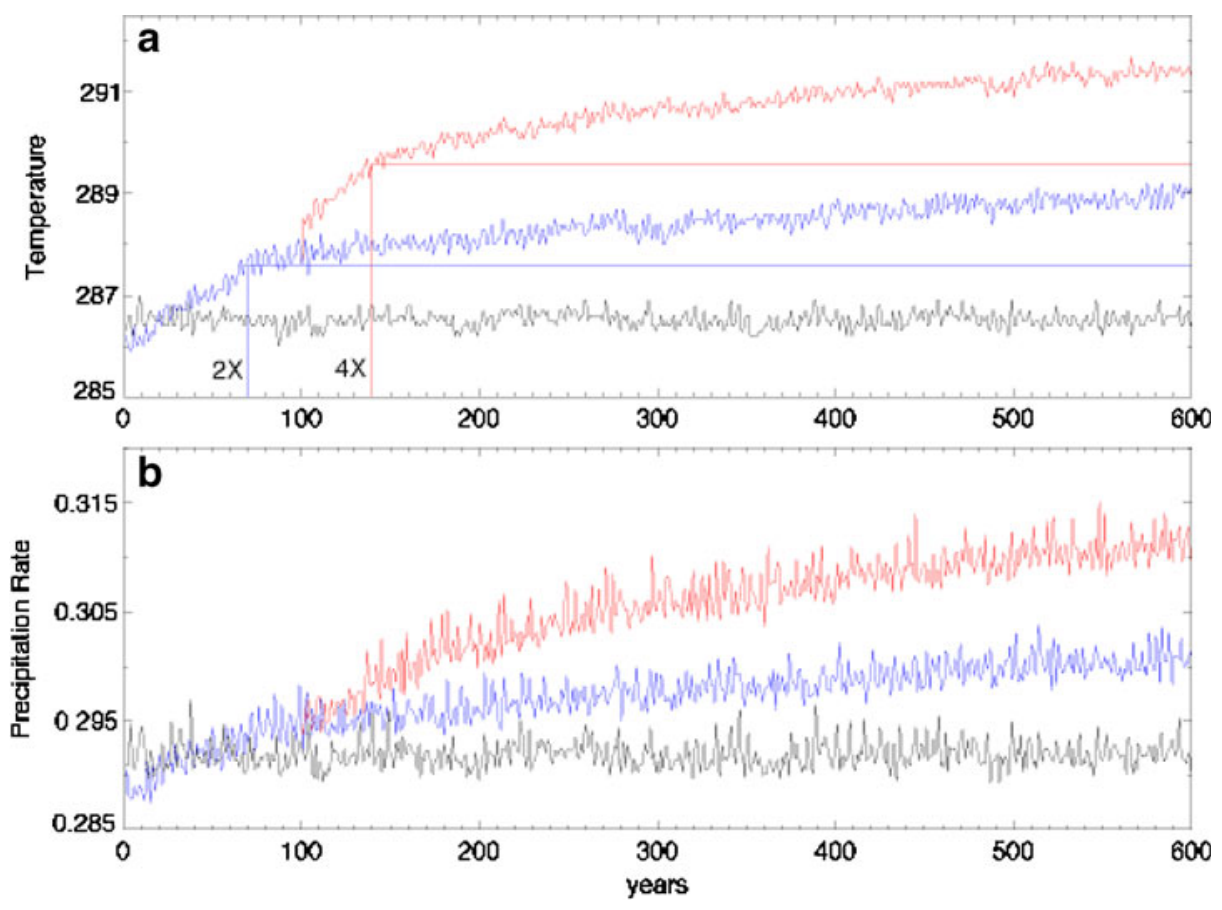

Fig. 1 Global mean $1 \%$ /year simulations to stabilizations at $2 \mathrm{x}$ and $4 \mathrm{xCO} 2$, respectively. a Surface air temperature $\left({ }^{\circ} \mathrm{K}\right)$ and $\mathbf{b}$ precipitation rate $(\mathrm{cm} /$ day). Curve identifications are: control integration (black lines), $2 \mathrm{X}$ integration (blue lines) and $4 \mathrm{X}$ integration (red lines). Time series are plotted out to the end of their respective integrations for $2 \mathrm{X}$ and $4 \mathrm{X}$. The vertical lines depict the time scales where the $\mathrm{CO} 2$ concentration is doubled (blue vertical line) and quadrupled (red vertical line), respectively. The horizontal lines indicate the basis from which the additional response of global mean surface air temperature can be evaluated for each integration after the $\mathrm{CO}_{2}$ is held fixed

corresponding comparison to a $4 \mathrm{X}$ mixed-layer integration carried out recently at GFDL. This implies that for both $2 \mathrm{X}$ and $4 \mathrm{X}$ radiative forcings, the time constants for their respective approaches to equilibrium are essentially identical. This topic regarding time constants was discussed in earlier studies (Manabe and Stouffer 1994; Manabe et al. 2004). In any event, it is clear that hydrologic processes take considerably longer to equilibrate than surface air temperature and that complete equilibrium of both quantities would take more than 1000 years to achieve even after the $\mathrm{CO}_{2}$ concentration has been stabilized.

\section{Statistical procedure}

The hydrological response to the two scenarios of $\mathrm{CO}_{2}$ increases will be evaluated by a Student's t-test for changes in the mean state and the standard F or ratio test for variance changes. However since both precipitation and runoff are bounded by zero, they are not normally distributed (Mearns 1993) and, therefore, it is necessary to apply a square root transformation to the original data if the $\mathrm{F}$ test is to be used (Brooks and Carruthers 1953; Panofsky and Brier 1968). Various tests 
were conducted to confirm that this transformation yielded approximately normally distributed data. However, this procedure has only been applied to the variance ratio computations, not the time means. Although it is true that the square root transformation is also bounded at zero, practically all of the analysis presented in this study, takes place from middle to higher latitudes where extreme dryness does not occur very often. Therefore, this should not be a major issue for the annual, seasonal and monthly mean data analyzed here.

For this study, the effective sample sizes were estimated from the time series of global annual mean precipitation rate using the lag-1 autocorrelation technique given by Laurmann and Gates (1977). The formula for estimating these effective sample sizes is given by:

$$
\mathrm{N}_{\text {eff }}=(1-\mathrm{r}) /(1+\mathrm{r}) * \mathrm{~N}
$$

where $r$ is the lag- 1 autocorrelation coefficient of each value of the time series with the value before it, $\mathrm{N}$ is the actual sample size (number of data points) and $\mathrm{N}_{\text {eff }}$ is the effective sample size of the time series. The corresponding degrees of freedom, df, is then given by: $\mathrm{df}=\mathrm{N}_{\text {eff }}-1$. Using this technique, the effective sample size for the control run of 900 points was found to be 452 and for the $2 \mathrm{X}$ and $4 \mathrm{X}$ time series of 160 points each, the values were 87 and 90 , respectively.

Student's t-tests and F tests based upon these modified sample sizes were, then, applied to the various hydrologic time series. According to the method of Vinnikov and Robock (2002), a quadratic function (Eq. 2 in the Appendix) is fitted separately at all grid points and that the spatial variances of deviations from that quadratic trend are then calculated for each point in time for each model ensemble member and averaged. The $\mathrm{F}$ or ratio test is defined as the transient variance of $2 \mathrm{X}$ and $4 \mathrm{X}$ distributions averaged over the 160 model year time series segments divided by the corresponding control variance distributions averaged over the entire 900 year time series. Both modified Student's t-tests and F tests are evaluated at the 5\% significance level for all results shown. In general, all figures from this point on represent differences between averages of 900 years of the control and the last 160 years of both transient integrations.

\section{Hydrologic response}

As noted in many previous investigations (Meehl et al. 2007), the hydrological cycle generally increases in response to greenhouse warming scenarios. General features in the geographical response of the annually averaged mean precipitation rate between the both the $2 \mathrm{X}, 4 \mathrm{X}$ and the control experiment are shown in Fig. 2a and $\mathrm{d}$ and include: an increase of precipitation in the tropical rainbelt region, an increase of precipitation in higher latitudes almost everywhere and a general decrease of precipitation in the subtropics. For obvious reasons, these differences are enhanced for the $4 \mathrm{X}$ as compared with the $2 \mathrm{X}$ experiment.

The general reduction of mean precipitation rate over the southern half of the U.S. and Europe would imply that these land areas experience drier conditions throughout most of the annual cycle. This will have an impact on the corresponding soil moisture changes as discussed later. Also notable is the excessive drying in the Sahel region (Held et al. 2005) and a general wetting over most of India. 



Fig. 2 Geographical distributions of annual mean difference between averages of 900 years of the control and the last 160 years of each transient integration for a mean precipitation rate for $2 \mathrm{X}$, b Student's t-test for the $2 \mathrm{X}$ distribution in a and $\mathbf{c}$ the ratio or $\mathrm{F}$ test for the corresponding $2 \mathrm{X}$ variance precipitation rate changes. Student's t-tests and F tests are based upon 452, 87, and 90 degrees of freedom for the control, $2 \mathrm{X}$ and $4 \mathrm{X}$ runs, respectively. Panels $\mathbf{d}$, e and $\mathbf{f}$ are the same distributions except for the $4 \mathrm{X}$ integration. The Student's t-test distributions have been normalized by the critical value of " $t$ " and, therefore, any values greater than 1 or less than -1 constitutes statistical significance at the $5 \%$ significance level. For the F test, values greater than 1.33 or less than .75 constitutes statistical significance at the $5 \%$ significance level. The square root transformation was used in c and $\mathbf{f}$. Units are in $\mathrm{cm} /$ day for the mean distributions in a and $\mathbf{d}$

Figure $2 \mathrm{~b}$, e assess the Students-t distributions at the $5 \%$ significance level corresponding to the annual mean changes shown in Fig. 2a, d, respectively. In general, practically all of the positive annual mean changes are statistical significant 
for both experiments in middle to higher latitudes as well as in the tropical rainbelt and India. The same is true for the negative changes in subtropical latitudes.

Since precipitation is zero bounded, an increase in the precipitation rate will generally result in an increase of its variance. This is shown by the ratio of annual mean precipitation variance of the $2 \mathrm{X}$ and $4 \mathrm{X}$ experiments to the variance of the control for both models (Fig. 2c, f). Here, it is seen that there is a general increase of variance from middle to higher latitudes for both models as well as in the tropical rainbelt. While these increases are significant at the 5\% significance level for the $2 \mathrm{X}$ experiment for only small scattered areas, they are generally significant for the 4X integration. Very few of the negative changes of variance in the subtropics are significant, however. An increase in daily precipitation variability in response to greenhouse warming was also noted in the study by Mearns et al. (1990) although their investigation only dealt with selected regions of the U.S.

Also, an analysis of the changes of mean precipitation variance shown above indicates that the generally positive changes in variance ratio in middle to higher latitudes are relatively small in comparison to the mean changes. A similar result was obtained from the studies by Raisanen (2002) and Hunt and Elliot (2004) which noted that although there were changes in interannual monthly mean precipitation variability in response to greenhouse warming, these were found to be relatively small in comparison to the time mean changes.

Mean precipitation rate zonally averaged over land areas generally increases in northern middle to high latitudes for almost all seasons except for the summer season in middle latitudes for both the $2 \mathrm{X}$ and $4 \mathrm{X}$ integrations (Fig. 3a, d) due to increased moisture transport from lower to higher latitudes (Manabe et al. 1981). This response has appeared in all AOGCMs simulating greenhouse warming (Meehl et al. 2007). Other features found in both the $2 \mathrm{X}$ and $4 \mathrm{X}$ integrations include increases of precipitation rate along equatorial latitudes for the entire year, decreases in southern subtropical latitudes for the entire year and decreases for November through August in northern subtropical latitudes.

The Student's t-tests for the monthly mean changes (Fig. 3b, e) reveal that, for both the $2 \mathrm{X}$ and the $4 \mathrm{X}$ integration, most of the middle to higher latitude mean changes are statistically significant, especially for the $4 \mathrm{X}$ case. This demonstrates that the stronger the forcing, the stronger the response and an increased likelihood of statistically significant changes. The $\mathrm{F}$ test at the $5 \%$ significance level for the variance changes (Fig. 3c, f) in middle to higher latitudes indicates no regions of statistical significance for the $2 \mathrm{X}$ case but does indicate statistically significant regions for most of the year for the $4 \mathrm{X}$ integration.

The mean changes in Fig. 3a, d in middle to higher latitudes are further illustrated by Fig. 4 which shows an increased wintertime precipitation rate in northern middle to higher latitudes (Fig. 4a, c) and a corresponding decrease in summertime precipitation rate over most land areas in northern middle latitudes (Fig. 4b, d). In particular, the decrease of summertime precipitation rate over the U. S. and Europe are important contributors to the increased summer dryness in these regions, a subject which will be discussed more fully in a succeeding section. An exception to this general drying is most of India where the precipitation rate actually increases during JJA, implying an increase of monsoonal rainfall there.

Both Students $\mathrm{t}$ and F tests were conducted on the distributions shown in Fig. 4. However since they generally resemble those shown in Fig. 2, e, c, and f, they are not 

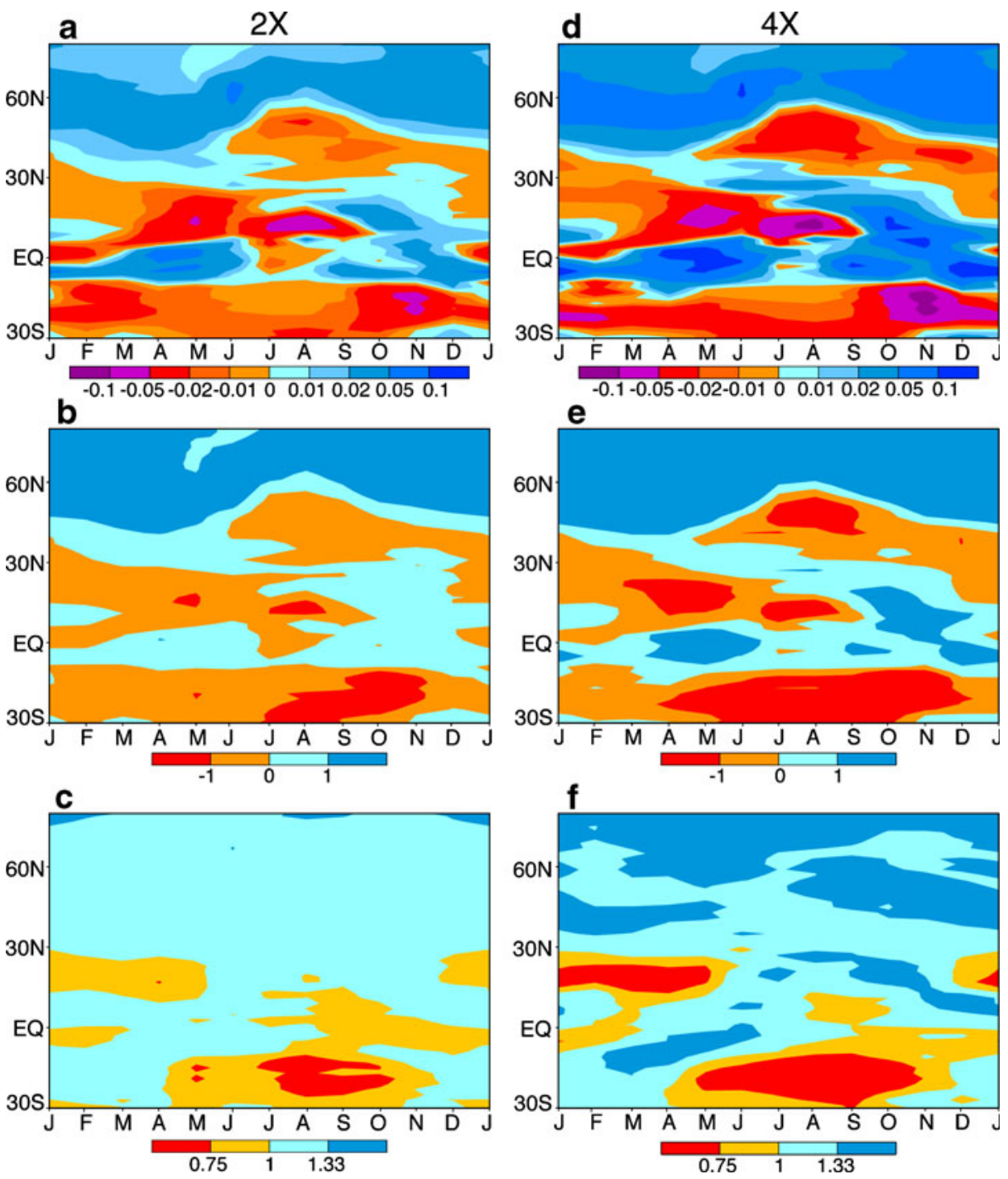

Fig. 3 Latitude-time distributions of zonally averaged difference for a mean precipitation rate for $2 \mathrm{X}$, b Student's t-test for the $2 \mathrm{X}$ distribution in a and $\mathbf{c}$ the ratio or $\mathrm{F}$ test for the corresponding $2 \mathrm{X}$ variance precipitation rate changes. Panels $\mathbf{d}$, e and $\mathbf{f}$ are the same distributions except for the $4 \mathrm{X}$ integration. Statistical test conditions are the same as in Fig. 2. Units are in $\mathrm{cm} /$ day for the mean distributions in a and $\mathbf{d}$

shown here. The results may be summarized as follows: Students t-tests show most of the differences of precipitation rate for $2 \mathrm{X}$ and $4 \mathrm{X}$ for both DJF and JJA to be significant at the $5 \%$ significance level. These include the reductions over the U.S. and Europe as well as the increase over most of India during JJA and the general increase in higher latitudes for both seasons. Variability changes generally follow the 

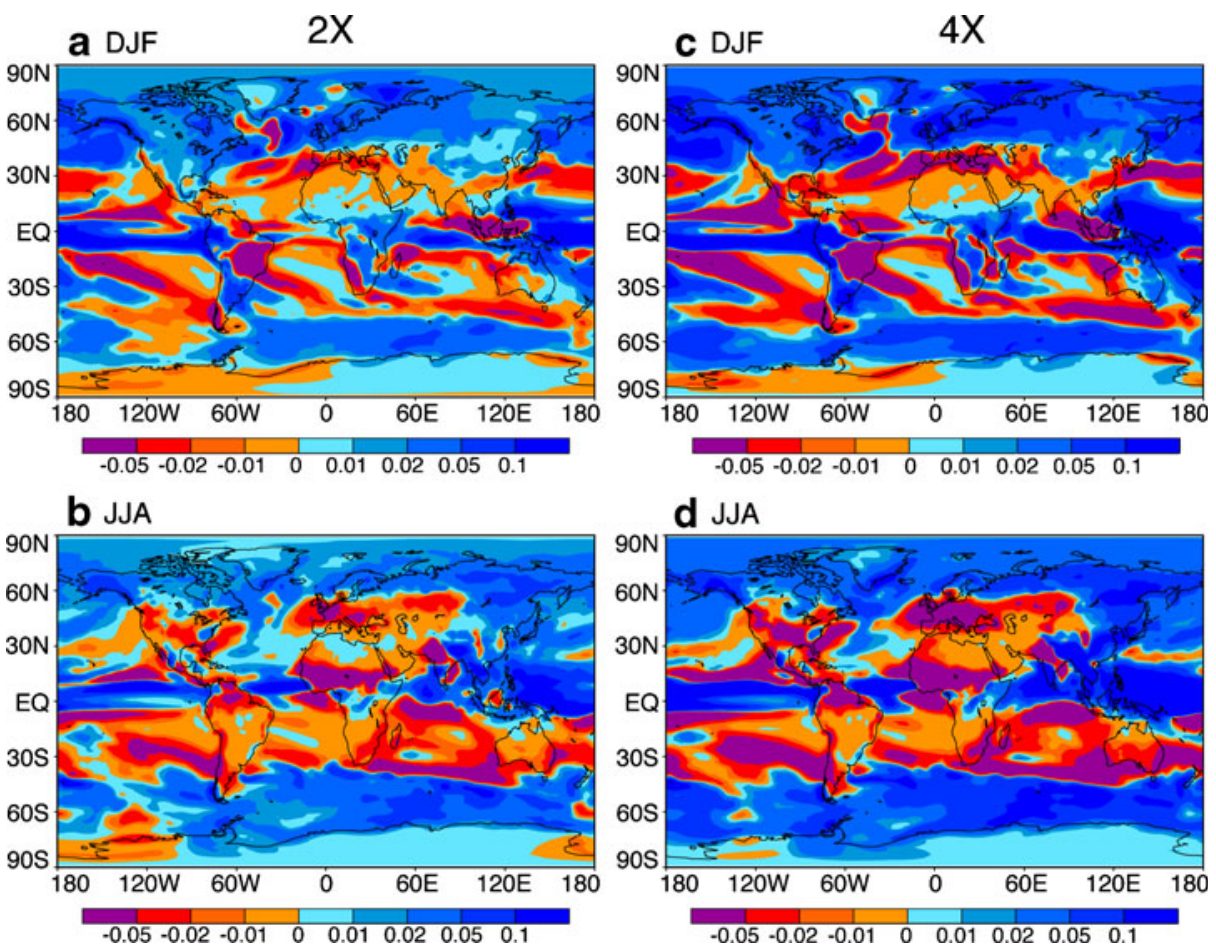

Fig. 4 Horizontal distribution of mean precipitation rate difference for both December-JanuaryFebruary $(D J F)$ and June-July-August $(J J A)$ seasons. Results are shown for the $2 \mathrm{X}$ model a DJF and $\mathbf{b}$ JJA; for the $4 \mathrm{X}$ model $\mathbf{c}$ DJF and d JJA. The averaging time periods are the same as in Fig. 2. Units are $\mathrm{cm} /$ day

same pattern as they did for annual mean precipitation rate (Fig. 2c, f); aside from small scattered patches in middle to higher latitudes, they are not significant for $2 \mathrm{X}$ for either season whereas they are more significant for $4 \mathrm{X}$. In particular for both DJF and JJA, these include significant increases in variability in middle to higher latitudes and decreases in the subtropics.

The patterns of mean runoff changes for both transient runs (Fig. 5a, d) are similar to those presented in several earlier studies (e.g. Manabe et al. 1981; Manabe and Wetherald 1987; Milly et al. 2002): increases in runoff during fall, winter and spring and decreases during the summer months in northern middle to higher latitudes (Cubasch et al. 2001; Meehl et al. 2007).

The Student's t-tests for mean runoff changes (Fig. 5b, e) and F tests for runoff variance changes (Fig. 5c, f) both indicate that the regions of runoff increases indicated in the time mean and variance fields in middle to higher latitudes are statistically significant at the $5 \%$ significance level from late fall to early spring and generally follow one another. Due to the larger radiative forcing and response, these changes are much larger and more significant in the $4 \mathrm{X}$ run than in the $2 \mathrm{X}$ run.

Both mean runoff and its variance increase in northern middle to higher latitudes for much of the year which is consistent with a greater likelihood of more extreme 


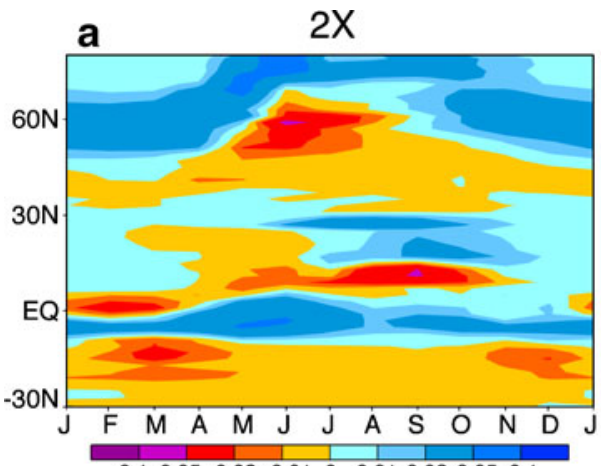

b
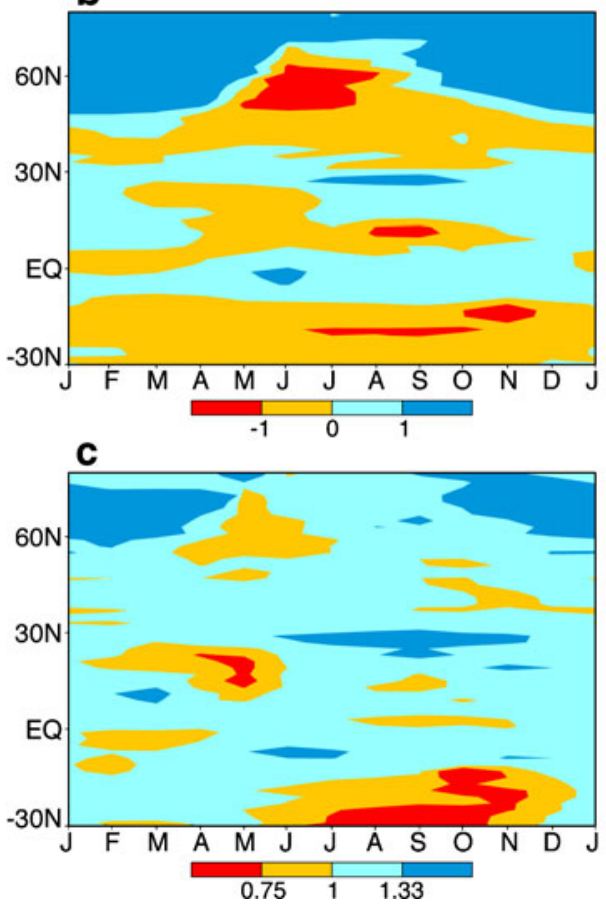

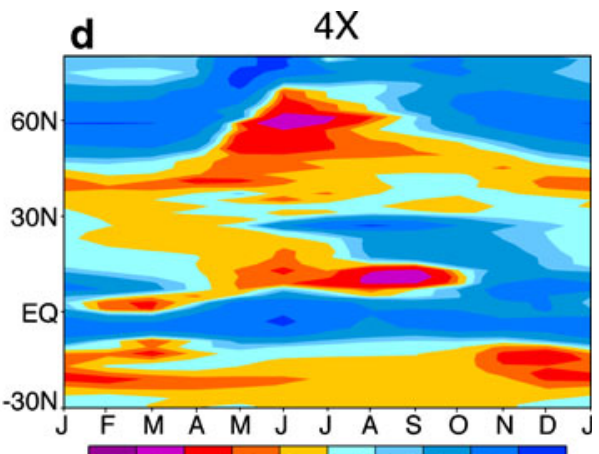

e
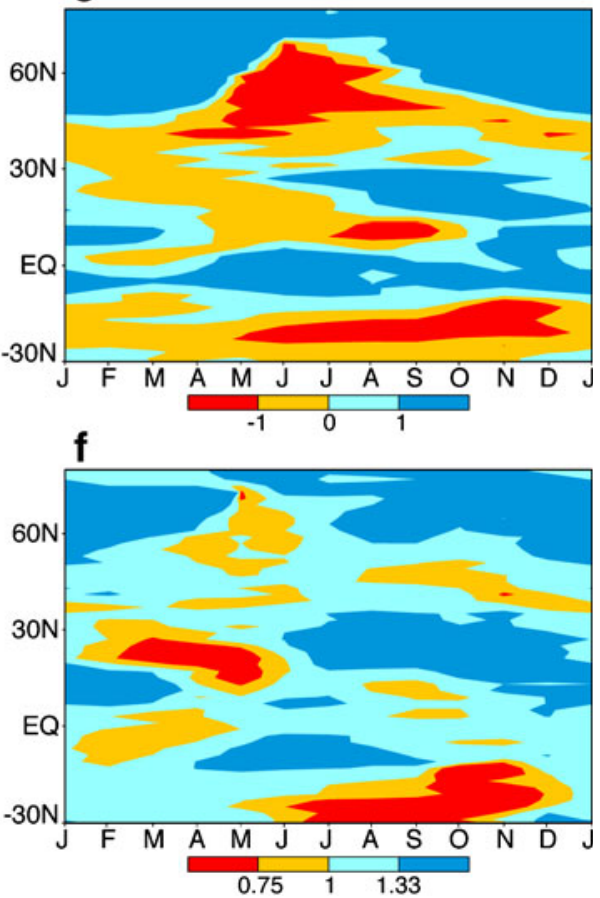

Fig. 5 Latitude-time distributions of zonally averaged difference for a mean runoff rate for $2 X, \mathbf{b}$ Student's t-test for the $2 \mathrm{X}$ distribution in $\mathbf{a}$ and $\mathbf{c}$ the ratio or $\mathrm{F}$ test for the corresponding $2 \mathrm{X}$ variance runoff rate changes. Panels $\mathbf{d}, \mathbf{e}$ and $\mathbf{f}$ are the same distributions except for the $4 \mathrm{X}$ integration. Statistical test conditions are the same as in Fig. 2 Units are in $\mathrm{cm} /$ day for the mean distributions in $\mathbf{a}$ and $\mathbf{d}$

river discharge events or frequency of "100 year" floods noted in Milly et al. (2002) and runoff increases in Wetherald and Manabe (2002), and Manabe et al. (2004). This conclusion is also in agreement with studies by Milly et al. (2005) and Nohara et al. (2006) who discussed the risks of extreme discharge events in response to increasing greenhouse gases by analyzing 12 and 19 different AOGCMs, respectively, using the SRES A1B scenario (Nakicenovic et al. 2000). 
These results are further highlighted by Fig. 6 which shows the geographical distributions of wintertime runoff changes. In general runoff increases occur in middle to higher latitudes over Asia, North America and northern Europe. Subsequent statistical tests on both the mean and variance changes show most of them to be statistically significant especially for the $4 \mathrm{X}$ integration.
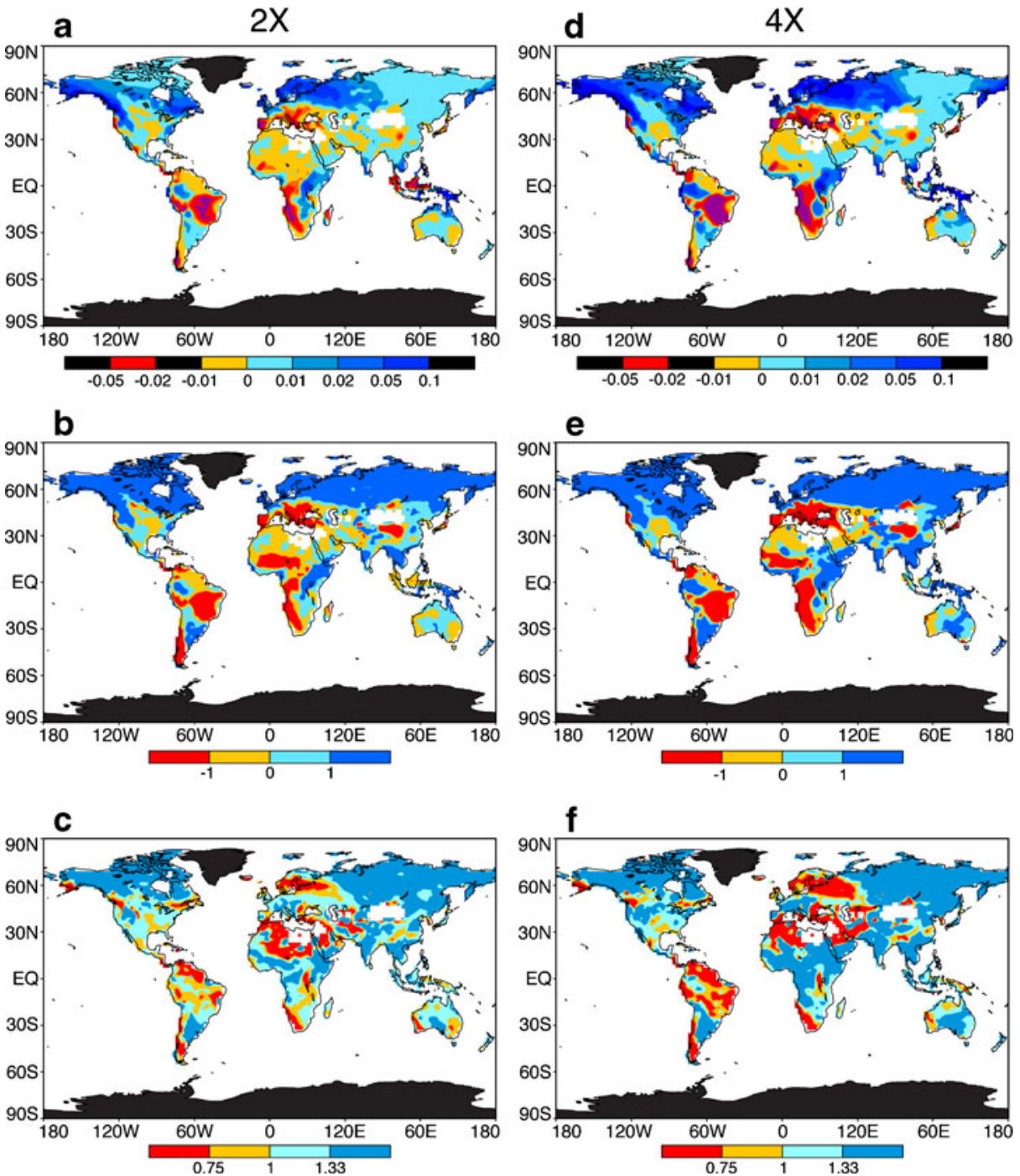

Fig. 6 Geographical distribution for the December-January-February (DJF) season of the a mean runoff rate difference for $2 \mathrm{X}$, b Student's t-test for the $2 \mathrm{X}$ distribution in a and $\mathbf{c}$ the ratio or F test for the corresponding $2 \mathrm{X}$ variance runoff rate changes. Panels $\mathbf{d}$, e and $\mathbf{f}$ are the same distributions except for the $4 \mathrm{X}$ integration. Statistical test conditions are the same as in Fig. 2 . Units are in $\mathrm{cm} / \mathrm{day}$ for the mean distributions in a and $\mathbf{d}$ 
It is generally noted that increases of runoff variance are greater than those for precipitation (compare Fig. 3c, f with Fig. 5c, f) especially for the $2 \mathrm{X}$ integration during the fall, winter and spring seasons. At least for the current CM2.1 model, the relatively small increases of precipitation variance are capable of producing greater runoff variance during these times.

The patterns of mean soil moisture change (Fig. 7a, d) in northern middle to higher latitudes follow those obtained in earlier studies (e.g. Manabe and Stouffer 1980; Wetherald and Manabe 1981; Manabe et al. 1981), namely wetter winters and dryer summers. The mechanisms responsible for the increased summertime drying have been extensively analyzed and include an earlier snowmelt season (and, therefore, earlier runoff), increased evaporation and a general reduction of low level humidity (e.g. Manabe et al. 1981; Wetherald and Manabe 1995, 2002; Cubasch et al. 2001; Findell and Delworth 2005). Decreases of summertime precipitation also play a major role in the continental summer drying (Fig. 4b, d). A similar pattern of summer dryness was also found by Wang (2005) by analyzing 15 different models with a variety of forcings including various SRES scenarios (Nakicenovic et al. 2000) and idealized $1 \%$ per year increases of $\mathrm{CO}_{2}$.

The Student's t-tests (Fig. 7b, e) indicates that the resulting summer dryness patterns for both the $2 \mathrm{X}$ and $4 \mathrm{X}$ integrations are statistically significant at the $5 \%$ significance level over fairly extensive regions. A similar result was obtained in Manabe et al. (1981) where a comparable analysis was carried out on an ensemble of eight separate integrations of an earlier version of a mixed-layer general circulation model with idealized geography subjected also to a quadrupling of $\mathrm{CO}_{2}$.

The corresponding geographical changes of area mean summertime soil moisture shown in Fig. 8a, c indicate excessive drying over Asia, North America and Europe, a feature noted in many previous studies (Manabe et al. 1981; Cubasch et al. 2001; Findell and Delworth 2005; Meehl et al. 2007) especially over the United States and Europe. Again, the changes are more severe and significant (Fig. 8b, d) according to the Students-t test for the $4 \mathrm{X}$ integration as compared with the $2 \mathrm{X}$ version.

Although the square root transformation produced distributions that were approximately normal for both precipitation and runoff, it was less successful with soil moisture since it is bounded both at zero and its respective field capacities which restricts the usefulness of the classical $F$ test for this quantity. For the sake of consistency however, the square root transformation was applied to this data also. In any event, simply the changes of soil moisture variance are shown in Fig. 7c, f. While no estimate of statistical significance is made on the basis of the F test, these panels nevertheless indicate that the variance difference of zonal monthly mean soil moisture increases during the summer months in middle to higher latitudes, with the increase being considerably larger for the $4 \mathrm{X}$ simulation as compared with the $2 \mathrm{X}$ run. These results suggest that there is an increased likelihood of more severe drying events during the summer season for both models in middle to higher latitudes, particularly for the $4 \mathrm{X}$ case in response to greenhouse warming.

The subject of drought occurrence in a greenhouse warming environment was evaluated and discussed by both Rind et al. (1990) and Mearns (1993). In particular, Rind et al. (1990) found in the GISS model that the occurrence of drought in a greenhouse warming atmosphere is driven more by increases of potential evapotranspiration rather than by changes of precipitation although precipitation is still important. For example, the study, employing two different drought indicies, 

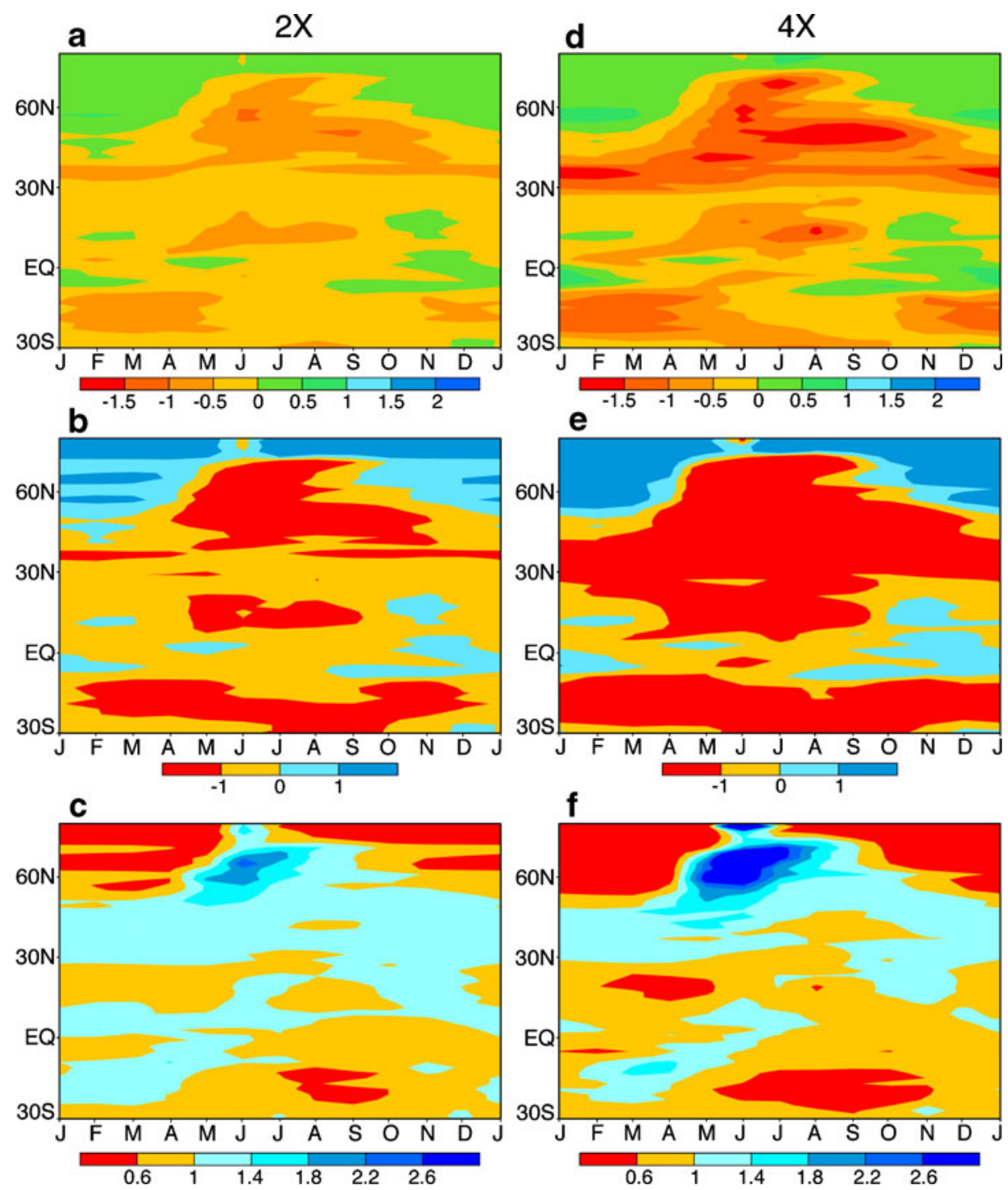

Fig. 7 Latitude-time distributions of zonally averaged difference for a mean soil moisture for 2X, b Student's t-test for the $2 \mathrm{X}$ distribution in a and $\mathbf{c}$ the ratio of transient to the control variance for the corresponding $2 \mathrm{X}$ variance precipitation rate changes. Panels $\mathbf{d}$, e and $\mathbf{f}$ are the same distributions except for the $4 \mathrm{X}$ integration. Units are in $\mathrm{cm}$. for $\mathbf{a}$ and $\mathbf{d}$. Units are in $\mathrm{cm}$. for the mean distributions in a and $\mathbf{d}$. The square root transformation was applied to the data prior to computing the distributions in $\mathbf{c}$ and $\mathbf{f}$ although the $\mathrm{F}$ test itself was not explicitly evaluated

indicated that drought over the United States could increase from 5 to $40 \%$ of the time by the middle of this century in a greenhouse warming scenario.

Mearns (1993) commentated that earlier studies with mixed-layer models may have underestimated both the severity and occurrence of drought due to the 

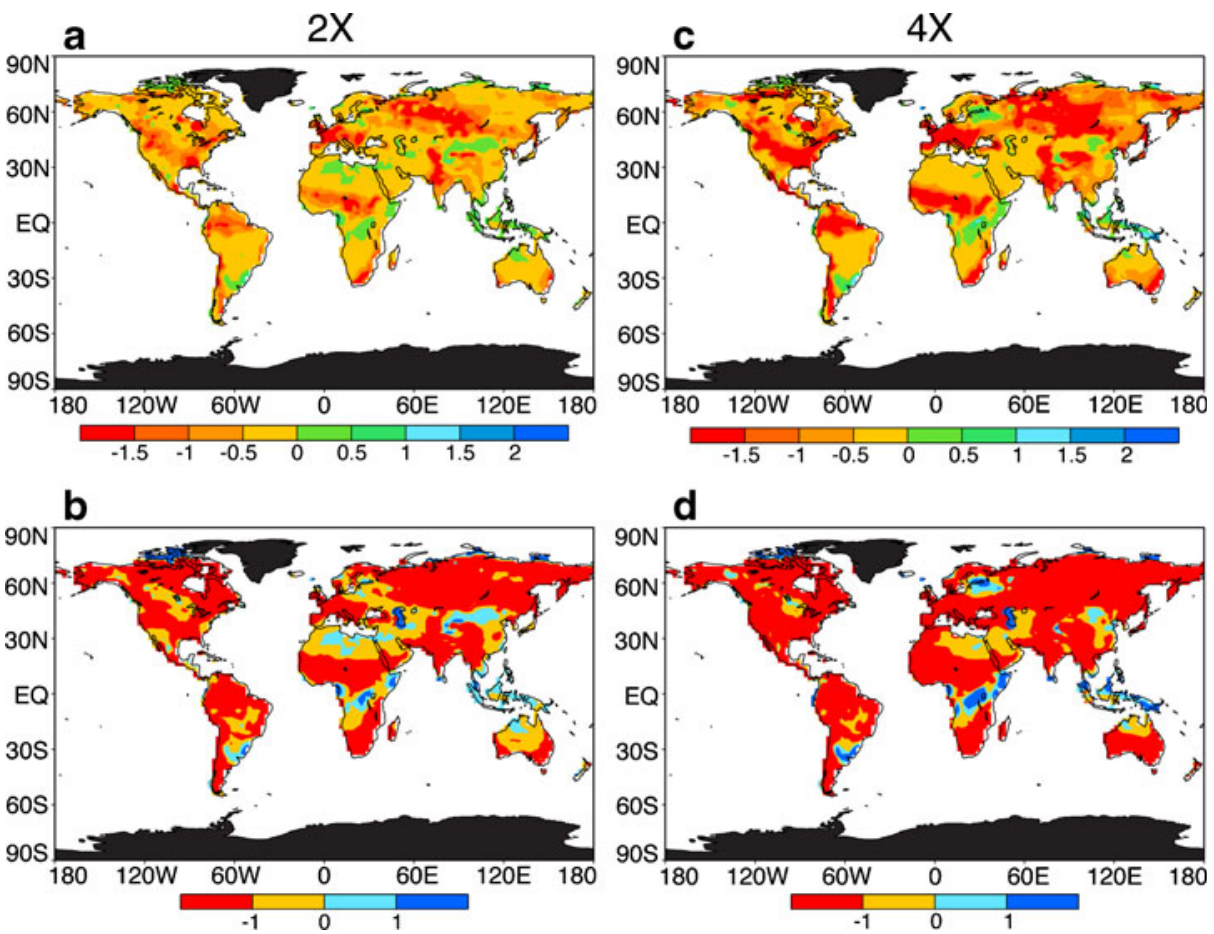

Fig. 8 Geographical distributions for the June-July-August (JJA) season of the a mean soil moisture difference for $2 \mathrm{X}$, b Student's t-test for the $2 \mathrm{X}$ distribution in a. Panels $\mathbf{c}$ and $\mathbf{d}$ are the same distributions except for the $4 \mathrm{X}$ integration. Statistical test conditions are the same as in Fig. 2. Units are in $\mathrm{cm}$ for the mean distributions in a and $\mathbf{c}$

simplicity of the soil moisture schemes used in these models. Mearns (1993) also stated that, because of the slower thermal response of the oceans, available moisture by evaporation from the ocean surfaces is reduced which would tend to enhance the summer drying process as compared with the earlier studies (Manabe et al. 1981). Both comments suggest that the latest generation of AOGCMs might be more successful in dealing with the occurrence and frequency of summertime drought. Obviously, this issue must be further investigated through the use of more realistic land surface schemes.

Figure $7 \mathrm{c}$, f also show that the variance decreases during the fall, winter and spring months in northern middle to higher latitudes. This is due to the fact that the soil moisture at these times and locations are fairly close to their field capacities and, therefore, cannot increase much further, thereby resulting in actual decreases of variance. This is not the case for the summer season where the soil moisture values are more in the middle of their allowable range and are freer to change.

The variance increases shown in Fig. 7c, f during the JJA season can be further analyzed by computing the trends of variance of soil moisture for the entire 600 year time series for both the $2 \mathrm{X}$ and $4 \mathrm{X}$ integrations as shown in Fig. 9. Here, again, the 


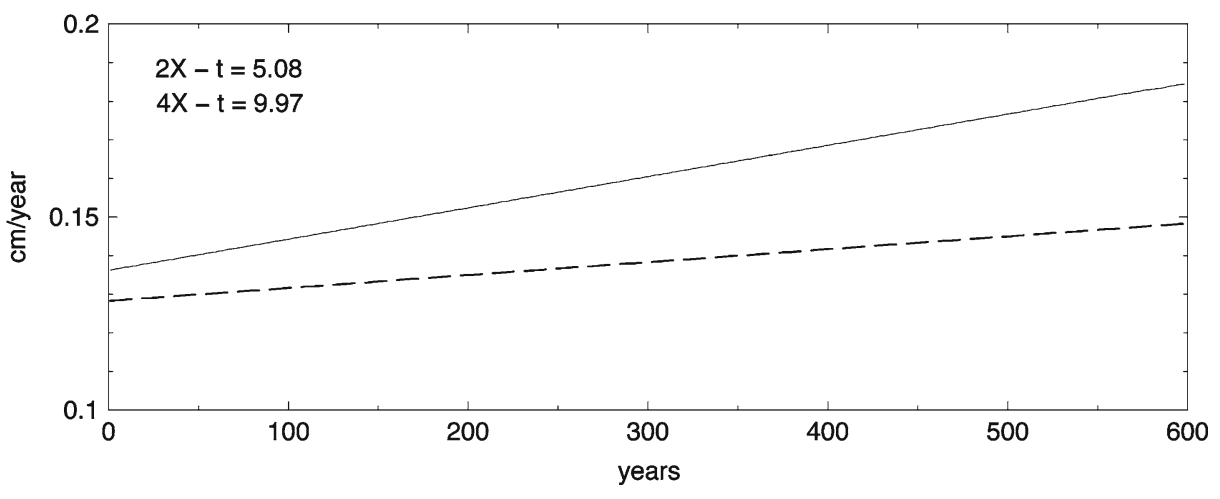

Fig. 9 Variance time series trend of soil moisture for both $2 \mathrm{X}$ (dashed line) and $4 \mathrm{X}$ (solid line) integrations as computed by linear least squares and integrated over the zonal belt of $45-60^{\circ} \mathrm{N}$ latitude taken over the entire 600 year periods. The slope of each line is given by the coefficient b2 (see Eq. 3 in the Appendix) for each case. Units are in $\mathrm{cm}$. The square root transformation has been applied to the data prior to computing these slopes. The values of " $\mathrm{t}$ " for the Students $\mathrm{t}$-test are given in the upper left hand corner and indicate significantly different slopes from zero at the $1 \%$ significance level or more

VR method is used to compute the trend of the variance time series for each model for the latitudinal zone of $45-60^{\circ} \mathrm{N}$. Variances are computed by the same method as described previously but are further processed by fitting them to linear trends (Eq. 3 in the Appendix). Here, the square root transformation has been applied to the data prior to computing these slopes.

Both the $2 \mathrm{X}$ and $4 \mathrm{X}$ models (Fig. 9) exhibit positive slopes of precipitation variance change, the magnitude of the slope for $4 \mathrm{X}$ being approximately double that for $2 \mathrm{X}$. This figure indicates that the variance of JJA soil moisture is strongly increasing in middle to higher northern latitudes with both slopes being significantly different from zero according to the students-t test at the $1 \%$ significance level or greater.

Another method to demonstrate this is to construct, frequency plots of the local soil moisture values from both the $2 \mathrm{X}$ and $4 \mathrm{X}$ integrations to demonstrate the overall changes in soil moisture variability in the zonal belt of $45^{\circ} \mathrm{N}$ to $60^{\circ} \mathrm{N}$. In both integrations, there is a tendency for the frequency distribution of the raw soil moisture data to shift towards smaller values as greenhouse gases increase (Fig. 10a, d). This shows that the soil moisture is generally decreasing in the zonal region of $45-60^{\circ} \mathrm{N}$ during JJA as discussed above. An examination of the frequency plots in Fig. 10b, c, e and f, which have been normalized by removing the means, reveals that there is a slight shift towards a drier climate in the transient integrations. The curves in Fig. 10b, $d$ indicate that negative values increase over a larger range, implying that the transient distribution is both shifting toward negative values and broadening. Therefore in both integrations, the changes in the normalized frequency distributions (Fig. 10b, c, e, f) indicate a reduction and broadening of the curves for the transient integrations which suggests that the variance of soil moisture would increase during the summer months. 

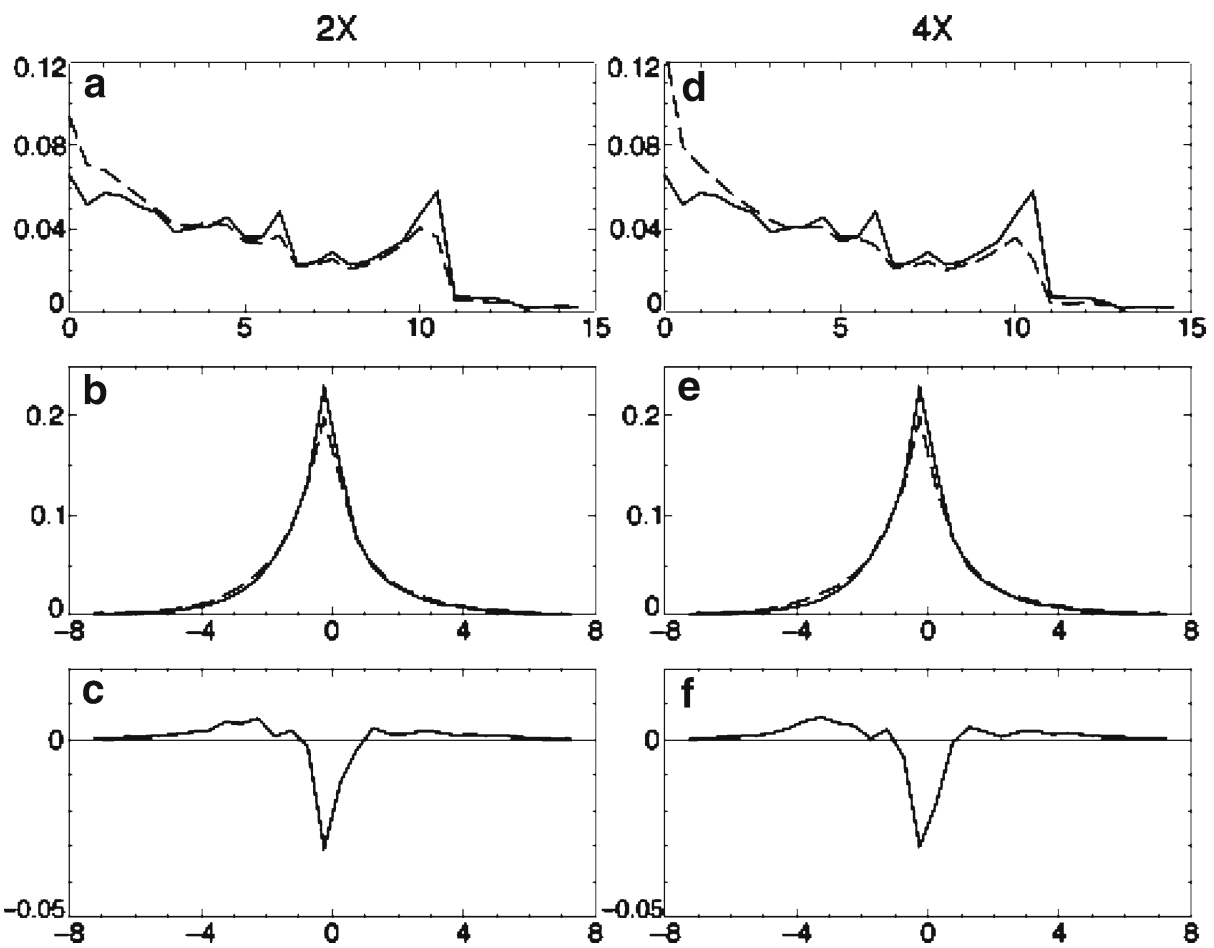

Fig. 10 Frequency distributions computed over the zonal belt of $45-60^{\circ} \mathrm{N}$ for occurrences of JJA soil moisture. In the top four panels, the solid lines represent data from the control integrations and the dashed lines, the perturbation integrations. a $2 \mathrm{X}$ values. d $4 \mathrm{X}$ values. b normalized $2 \mathrm{X}$ distributions, e normalized $4 \mathrm{X}$ distributions, c normalized $2 \mathrm{X}$ difference between the transient and control integrations shown in $\mathbf{b}, \mathbf{f}$ normalized $4 \mathrm{X}$ difference between the transient and control shown in c. The distributions were normalized by removing the local mean at each grid point in each integration to clearly show the shifts in the distributions. Units are in $\mathrm{cm}$ for the $\mathrm{x}$-axis, frequency ratios for the y-axis

\section{Discussion}

Hydrologic response to greenhouse warming is investigated by use of an AOGCM with two idealized projections of radiative forcing, namely a doubling and a quadrupling of $\mathrm{CO}_{2}$ concentration. The latter case is most important in that it provides a large enough signal so that statistical significance can be established for many of the changes both in time mean state and variance. Results of this study strongly suggest that there are systematic changes in certain hydrologic quantities such as precipitation rate, runoff rate and soil moisture in response to greenhouse warming that could lead to an increased magnitude and frequency of both excessive river discharges and periods of summertime dryness.

Generally, increases of precipitation variance in middle to higher northern latitudes throughout the year impact other hydrological variables such as runoff and soil moisture in these latitude regions. In particular, increases in precipitation variance generally lead to increases in runoff variance during winter, early spring and fall in middle to higher latitudes which turned out to be statistically significant at the 
$5 \%$ significance level, especially for the $4 \mathrm{X}$ integration. It is noted that, in general, variance increases of runoff exceed those of precipitation especially for the fall, winter and spring seasons. Apparently, relatively small increases in precipitation variability are capable of triggering larger responses of runoff variability during these times. Although the F test was not strictly applicable to soil moisture, there is a marked tendency for increased variance of summertime soil moisture in middle to higher latitudes where the time mean state is reduced. In addition, an analysis of the entire time series of both $2 \mathrm{X}$ and $4 \mathrm{X}$ integrations indicate positive slopes or tends of variance for summertime soil moisture in the $45-60^{\circ} \mathrm{N}$ region which are significantly different from zero.

The results illustrated in this study, taken together, support the statements made in various IPCC reports (i.e. Houghton et al. 1990, 1995, 2001; Meehl et al. 2007) that greenhouse warming has the potential of causing increased occurrences and magnitudes of extreme weather events both wet and dry. In particular, Randall et al. (2007), is quoted as stating "In a warmer future climate, most AOGCMs project increased summer dryness and winter wetness in most parts of the northern middle and higher latitudes". However, despite this apparent agreement, the results of this investigation must still be regarded as tentative at the present time. In any event, this study has shown that very long time scales are necessary before the hydrologic changes illustrated here can be statistically established to a reasonable degree of certainty.

A recommendation at this point would be to perform a comparable type of analysis on the ensemble of integrations provided by the various modeling groups to the PCMDI data archives for at least one of the scenarios. Such a study would provide a much greater sample size and data base to analyze further the variance tendencies which have been presented here and establish more confidence in them.

Acknowledgements The author would like to thank Konstantin Vinnikov for his assistance in applying his analysis scheme to the model results. The author also wishes to thank Hyun-Chul Lee for setting up and integrating the $2 \mathrm{X}$ and $4 \mathrm{X}$ experiments for the CM2.1 model and Michael Spelman for his excellent assistance in running the SM2.1 4X experiment. Finally thanks are due to Syukuro Manabe, Kirsten Findell, John Lanzante and Ronald Stouffer for their helpful and constructive reviews.

Open Access This article is distributed under the terms of the Creative Commons Attribution Noncommercial License which permits any noncommercial use, distribution, and reproduction in any medium, provided the original author(s) and source are credited.

\section{Appendix-Computation of Variance}

The method proposed by Vinnikov and Robock (2002, VR) may be outlined as follows. Using the VR scheme and terminology, let $y(t), t=t_{1}, t_{2}, t_{3}, \ldots . . t_{n}$ be a time series of annual averages of some climate variable " $y$ " and let " $t$ " be the year number (in this example, $\mathrm{y}(\mathrm{t})$ is the annually averaged precipitation rate). Assuming that the expected value, $\mathrm{E}\{\mathrm{y}(\mathrm{t})\}$ may be defined by a quadratic curve, we have that

$$
\mathrm{Y} 1(\mathrm{t})=\mathrm{E}\{\mathrm{y}(\mathrm{t})\}=\mathrm{a}_{1}+\mathrm{b}_{1} * \mathrm{t}+\mathrm{c}_{1} * \mathrm{t}^{2}
$$


The coefficients a1, b1 and c1 may be estimated by a standard least squares technique. Once this is done, the perturbations about this quadratic curve may be computed using Eq. 2.

$$
\mathrm{y}^{\prime}(\mathrm{t})=\mathrm{y}(\mathrm{t})-\mathrm{Y} 1(\mathrm{t})=\mathrm{y}(\mathrm{t})-\mathrm{a}_{1}-\mathrm{b}_{1} * \mathrm{t}-\mathrm{c}_{1} * \mathrm{t}^{2}
$$

The variances are obtained as the anomalies about the quadratic curve, $\left(y^{\prime}(t)\right)^{2}$ for each point in the time series. The trend in the variance time series is simply a fit with a straight line of the form.

$$
\mathrm{Y} 2(\mathrm{t})=\mathrm{a} 2+\mathrm{b} 2 * \mathrm{t}
$$

Again, the coefficients a 2 and b2 are evaluated using a least squares technique. This latter quantity, b2 or the slope of the line, together with $y^{\prime}(t)^{2}$ will form the basis for the analysis presented in this paper. Therefore, b2 represents the trend of the variances.

The VR method has the desirable features that 1) it takes into account the fact that the mean state is changing throughout the transient experiments and 2) it provides an unambiguous time series of variances once the order of the polynomial to remove the mean is determined. A schematic of this method of analysis is shown in panels (a) and (b) of Fig. 11. Figure 11a shows the original time series at a grid point in higher latitudes with the quadratic mean curve (Eq. 2) fitted to the data from which the anomalies $\left(y^{\prime}(t)\right)$ are computed. Figure $11 b$ shows the resulting time series of variances computed from the information in panel (a) along with the linear curve (Eq. 3) fitted to the variance time series.

As noted above, the only unknown parameter in the VR method is the degree of the polynomial used to remove the trend. Vinnikov (personal communication) has indicated that, for most variables over the historical record, only a second order (or quadratic) polynomial is necessary to estimate the changes in the mean state. In order to test this conclusion, several of the fields shown in this paper were recalculated using a third order polynomial. It was found that the variance changes were almost identical to the ones obtained from using the second order polynomial. Based upon
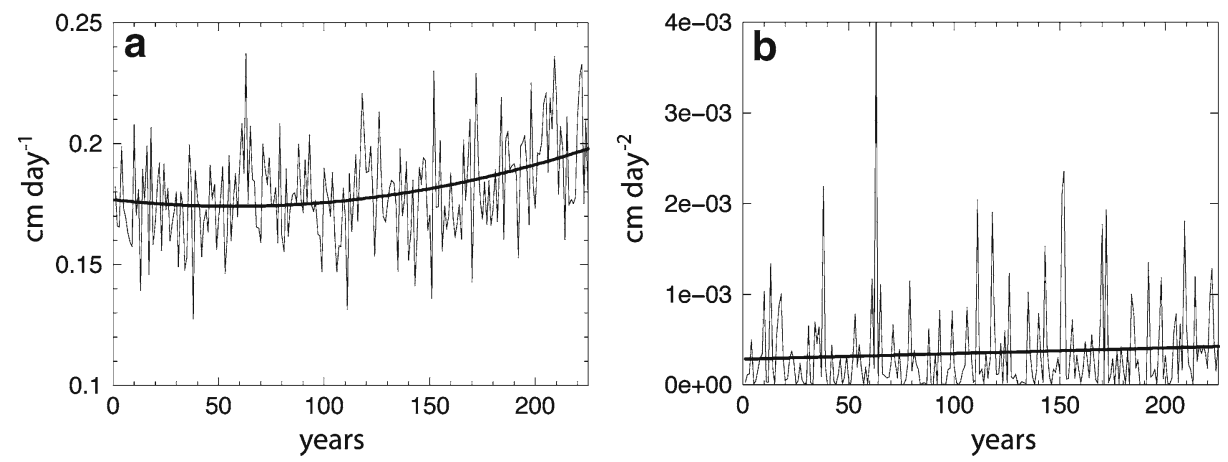

Fig. 11 a A typical time series of precipitation at a single grid point in high latitudes (thin line) and the quadratic curve (Eq. 1 in the Appendix) fitted to that time series (thick line); b time series of variances computed for the same point (thin line) and the corresponding linear fit (Eq. 3 in the Appendix) to those variances (thick line). Units for $\mathbf{a} \mathrm{cm} / \mathrm{day}$, for $\mathbf{b}(\mathrm{cm} / \mathrm{day})^{2}$ 
this analysis, it was decided to use the VR method with a second order polynomial in the results presented throughout this paper.

\section{References}

Benestad, RE (2006) Can we expect more extreme precipitation on the monthly time scale? J Clim 19:630-637

Brooks CP, Carruthers N (1953) Handbook of statistical methods in meteorology. Her Majesty's Stationary Office, London

Cubasch UG, Meehl GA, Boer GJ, Stouffer RJ, Dix M, Noda A, Senior CA, Raper S, Yap KS, Abe-Ouchi A, Brinkop S, Classen M, Collins M, Evans J, Fischer-Bruns I, Flato G, Fyfe JC, Ganopolski A, Gregory JM, Hu Z-Z, Joos F, Knutson TR, Knutti R, Landsea C, Mearns LO, Milly PCD, Mitchell JFB, Nozawa T, Paeth H, Raisanen J, Sausen R, Smith S, Stocker T, Timmermann A, Ulbrich U, Weaver A, Wegner J, Whetton P, Wigley T, Winton M, Zwiers F (2001) Projections of future climate change, chapter 9. In: Climate change 2001: the scientific basis. Contribution of working group I to the third assessment report of the intergovernmental panel on climate change. Cambridge University Press, Cambridge

Delworth TL, Broccoli AJ, Rosati A, Stouffer RJ, Balaji V, Beesley JT, Cooke WF, Dixon KW, Dunne J, Durachta JW, Findell KL, Ginoux P, Gnanadesikan A, Gordon CT, Griffies SM, Gudgel R, Harrison MJ, Held IM, Hemler RS, Horowitz LW, Klein SA, Knutson TR, Kushner PJ, Langenhorst AR, Lee H-C, Lin S-J, Lu J, Malyshev L, Milly PCD, Ramaswamy V, Russell J, Schwarzkopf MD, Shevliakova E, Sirutis JJ, Spelman MJ, Stern WF, Winton M, Wittenberg AT, Wyman B, Zeng F, Zhang R (2006) GFDL's CM2 global coupled climate models-part I: formulation and simulation characteristics. J Clim 19:643-674

Findell KL, Delworth TL (2005) A modeling study of dynamic and thermodynamic mechanisms for summer drying in response to global warming. Geophys Res Lett 32:16702-16702

Held IM. Delworth TL, Lu J, Findell KL, Knutson TR (2005) Simulation of Sahel drought in the 20th and 21st centuries. Proc Natl Acad Sci 102(50):17891-17896

Houghton JT, Jenkins GJ, Ephraums JJ (eds) (1990) Climate change: The IPCC scientific assessment. Cambridge University Press, New York, 365 pp

Houghton JT, Meira Filho LG, Callender BA, Harris N, Kattenberg A, Maskell K (eds) (1995) Climate change 1995: the science of climate change. Cambridge University Press, New York, $572 \mathrm{pp}$

Houghton JT, Ding Y, Griggs DJ, Noguer M, van der Linden PJ, Dai X, Maskell K, Johnson CA (eds) (2001) Climate change 2001: the scientific basis. Cambridge University Press, New York, $881 \mathrm{pp}$

Hunt BG, Elliot TI (2004) Interaction of climatic variability with climate change. Atmosphere-Ocean 42:145-172

Laurmann J, Gates L (1977) Statistical consideration in the evaluation of climate experiments with atmospheric general circulation models. J Atmos Sci 34:1187-1199

Manabe S (1969) Climate and ocean circulation, part I, the atmospheric circulation and hydrology of the earth's surface. Mon Weather Rev 97:739-774

Manabe S, Stouffer RJ (1980) Sensitivity of a global climate model to an increase of $\mathrm{CO}_{2}$ concentration in the atmosphere. J Geophys Res 85:5529-5554

Manabe S, Stouffer RJ (1994) Multiple-century response of a coupled ocean-atmosphere model to an increase of atmospheric carbon dioxide. J Clim 7:5-23

Manabe S, Wetherald RT (1987) Large-scale changes of soil wetness induced by an increase in atmospheric carbon dioxide. J Atmos Sci 44:1211-1235

Manabe S, Wetherald RT, Stouffer RJ (1981) Summer dryness due to an increase of atmospheric $\mathrm{CO} 2$ concentration. Clim Change 3:347-386

Manabe S, Wetherald RT, Milly PCD, Delworth TL, Stouffer RJ (2004) Century-scale change in water availability: $\mathrm{CO}_{2}$-quadrupling experiment. Clim Change 64:59-76

Mearns LO (1993) Implications of global warming for climate variability and the occurrence of extreme climate events. In: Wilhite DA (ed) Drought and assessment management and planning: theory and case studies. Kluwer, Boston, pp 109-130

Mearns LO, Schneider SH, Thompson SL, McDonald LR (1990) Analysis of climate variability in general circulation models: comparison with observations and changes in variability in $2 \mathrm{xCO} 2 . \mathrm{J}$ Geophys Res 95:20469-20489 
Meehl GA, Stocker TF, Collins WD, Friedlingstein P, Gaye AT, Gregory JM, Kitoh A, Knutti R, Murphy JM, Noda A, Raper SCM, Watterson IG, Weaver AJ, Zhao Z-C (2007) Global climate projections. In: Climate change 2007: the physical science basis, working group I contribution to the fourth assessment report of the intergovernmental panel on climate change. Cambridge University Press, Cambridge

Milly PCD, Shmakin AB (2002) Global modeling of land water and energy balances. Part I: the land dynamics (LaD) model. J Hydrometeorol 3:283-299

Milly PCD, Wetherald RT, Dunne KA, Delworth TL (2002) Increasing risk of great floods in a changing climate. Nature 415:514-517

Milly PCD, Dunne KA, Vecchia AV (2005) Global pattern of trends in streamflow and water availability in a changing climate. Nature 438:347-350

Moorthi S, Suarez MJ (1992) Relaxed Arakawa-Schubert: a parameterization of moist convection for general circulation models. Mon Weather Rev 120:978-1002

Nakicenovic N, Alcamo J, Davis G, de Vries B, Fenhann J, Gaffin S, Gregory K, Grubler A, Jung TY, Kram T, La Rovere EL, Michaelis L, Mori S, Morita T, Pepper W, Pitcher H, Price L, Raihi K, Roehrl A, Rogner H-H, Sankovski A, Schlesinger M, Shukla P, Smith S, Swart R, van Rooigen S, Victor N, Dadi Z (2000) IPCC special report on emissions scenarios. Cambridge University Press, Cambridge, $599 \mathrm{pp}$

Nohara D, Kitoh A, Hosaka M, Oki T (2006) Impact of climate change on river discharge projected by multimodel ensemble. J Hydrometeorol 7:1076-1089

Panofsky HA, Brier GW (1968) Some applications of statistics to meteorology. The Pennsylvania State University, University Park

Raisanen J (2002) $\mathrm{CO}_{2}$-induced changes in interannual temperature and precipitation variability in 19 CMIP2 experiments. J Clim 15:2395-2411

Randall DA, Wood RA, Bony S, Colman R, Fichefet T, Fyfe J, Kattsov V, Pitman A, Shukla J, Srinivasan J, Stouffer RJ, Sumi A, Taylor KE (2007) Climate models and their evaluation. In: Climate change 2007: the physical science basis, working group I contribution to the fourth assessment report of the intergovernmental panel on climate change. Cambridge University Press, Cambridge

Rind D, Goldberg R, Hansen J, Rosensweig C, Ruedy R (1990) Potential evapotranspiration and the likelihood of future drought. J Geophys Res 95:9983-10004

Rotstayn LD (1997) A physically based scheme for the treatment of stratiform clouds and precipitation in large-scale models. Part I: description and evaluation of microphysical processes. Q J R Meteorol Soc 123:1227-1282

Stouffer RJ (2004) Time scales of climate response. J Clim 17:209-217

Stouffer RJ, Manabe S (1999) Response of a coupled ocean-atmosphere model to increasing atmospheric carbon dioxide: sensitivity to the rate of increase. J Clim-Part I 12:2224-2237

Stouffer RJ, Wetherald RT (2007) Changes of variability in response to increasing greenhouse gases. Part I: temperature. J Clim 20:5456-5470

Stouffer RJ, Broccoli AJ, Delworth TL, Dixon KW, Gudgel R, Held I, Hemler R, Knutson T, Lee H-C, Schwarzkopf D, Soden B, Spelman MJ, Winton M, Zeng F (2006) GFDL's CM2 global coupled climate models—part 4: idealized climate response. J Clim 19:723-740

Tiedtke M (1993) Representation of clouds in large-scale models. Mon Weather Rev 121:3040-3061

Vinnikov KY, Robock A (2002) Trends in moments of climate indices. Geophys Res Lett 29:14-114-4

Wang G (2005) Agricultural drought in a future climate: results from fifteen models participating in the IPCC 4th assessment. Clim Dyn 25:739-753

Wetherald RT, Manabe S (1981) Influence of seasonal variation upon the sensitivity of a model climate. J Geophys Res 86:1194-1204

Wetherald RT, Manabe S (1995) The mechanisms of summer dryness induced by greenhouse warming. J Clim 8:3096-3108

Wetherald RT, Manabe S (2002) Simulation of hydrologic changes associated with global warming. J Geophys Res 107:4379-4394

Wetherald RT, Stouffer RJ, Dixon KW (2001) Committed warming and its implications for climate change. Geophys Res Lett 28:1535-1538 